\title{
Perencanaan Sudu Turbin Angin Untwisted Kapasitas 300 Watt Menggunakan NACA 4417
}

\author{
Abrar Ridwan \\ Teknik Mesin Universitas Muhammadiyah Riau \\ Laboratorium Konversi Energi Universitas Muhammadiyah Riau \\ E-mail:abrar.ridwan@umri.ac.id
}

\begin{abstract}
Abstrak
Pemanfaatan energi berkelanjutan merupakan usaha yang tidak pernah berhenti dilakukan oleh ilmuwan dan praktisi, salah satunya pembangkit listrik turbin angin. Potensi angin diatas gedung rektorat lantai 7 Universitas Muhammadiyah Riau berkisar $4-7 \mathrm{~m} / \mathrm{s}$ dan nilai tersebut sangat berpotensi untuk membantu suplai daya listrik ke gedung tersebut. Telah dilakukan perencanan dimensi sudu turbin dan bentuk aerofoil dengan referensi NACA 4417 berkapasitas daya 300 watt, radius sudu turbin 2,4 meter dengan tipe untwisted didapat nilai chord dipangkal (root) 0,730 m dan diujung (tip) 0,124 m sedangkan ketebalan maksimum chord dipangkal 0,186 m dan diujung 0,015 m. Gaya maksimum aksial turbin adalah 119 N. Bentuk disain akan menjadi parameter pembuatan sudu turbin berbahan baku unggulan lokal berupa limbah pelepah sawit.
\end{abstract}

Kata kunci : NACA 4417, sudu, chord, root dan tip

\section{Pendahuluan}

Keterlibatan ilmuan dan para enjineer tidak pernah lepas dari inovasi dan konservasi energi baru terbarukan. Banyak teknologi yang ditawarkan bergantung dengan potensi daerah yang dimiliki. Salah satu contoh provinsi riau memiliki limbah sawit yang melimpah sehingga berpotensi sebagai bahan bakar energi baru terbarukan untuk mesin diesel, daerah Indonesia timur berpotensi diterapkan pembangkit turbin angin dikarenakan kecepatan angin disana ratarata diatas $3 \mathrm{~m} / \mathrm{s}$. Sehingga potensi tersebut diatas akan menjadi ikon dan unggulan untuk masing - masing daerah. Dilihat dari kecepatan angin dari data BMKG, potensi di Provinsi Riau khususnya Pekanbaru masih tergolong sangat rendah. Akan tetapi potensi tersebut dapat dialihkan dari kecepatan angin yang tersedia diatas gedung lantai 7 rektorat Universitas Muhammadiyah Riau (UMRI) yaitu berkisar 4 $7 \mathrm{~m} / \mathrm{s}$. Potensi tersebut cukup untuk membangkit listrik kapasitas 300 Watt. Hal yang melatar-belakangi penulisan jurnal adalah melihat potensi angin yang sangat besar, kebutuhan suplai daya pembantu yang sangat diperlukan bagi gedung rektorat UMRI, dan melakukan disain awal untuk sudu yang merupakan komponen utama dari pembangkit turbin angin.
Perencanaan sudu turbin akan menggunakan bahan baku lokal unggulan daerah yaitu limbah pelepah sawit, sedangkan untuk bentuk dan dimensi aerofoil menggunakan persamaan pendekatan yang ada di referensi dibantu dengan software Qblade NACA 4417. Untuk mendapatkan turbin angin yang baik, perlu didisain strukturnya secara teoritis sehingga nantinya dapat dihasilkan energi kinetik yang digunakan untuk memutar generator. Masalah yang paling utama dalam perencanaan pembangkit turbin angin adalah bentuk aerofoil dari sudunya. Turbin angin dapat dibagi menjadi dua tipe yaitu sumbu horizontal dan vertikal dimana yang paling banyak menjadi perhatian adalah sumbu horizontal. Bentuk keseluruhan dari turbin yang akan dibangun tampak pada gambar 2. yaitu sudu, hub, tiang penahan, alternator (generator) dan basemen. Akan tetapi paper ini fokus pada perencanaan aerofoil sudu turbin pembangkit berkapasitas 300 watt.

\subsection{Parameter disain sudu turbin.}

Sudu turbin yang akan dibangun rencananya akan diletak diatas gedung lantai 7 Rektorat UMRI, sementara data kecepatan awal dan temperatur telah diambil dari jam 10:00 pagi sampai jam 16:00 dengan kecepatan minimal 4 $\mathrm{m} / \mathrm{s}$ dan maksimal $7 \mathrm{~m} / \mathrm{s}$, temperatur udara 
lingkungan $34{ }^{\circ} \mathrm{C}$ pada ketinggian lebih kurang $30 \mathrm{~m}$. dengan densitas udara $1,225 \mathrm{~kg} / \mathrm{m}^{3}$. Dari data tersebut diatas persamaan Betz dapat diterapkan untuk menghitung daya $\mathrm{P}$ dari putaran angin. Penggunaan kecepatan minimum agar putaran motor bisa dijaga konstan dengan menggunaan redukser.

$$
P=\frac{1}{2} \rho S C_{p} v^{3}
$$

Dimana $\rho$ adalah densitas udara yang berhubungan dengan temperatur dan ketinggian, $C_{p}$ adalah koefisien daya yang dapat ditentukan dari eksperimental $S$ merupakan luas area sapuan angin dan $V$ adalah kecepatan angin. Tip speed rasio (TSR) adalah perbandingan kecepatan rotasional rotor poros terhadap kecepatan translasi angin $(\lambda)$. Pada penelitian ini koefisien power $\mathrm{Cp}$ telah ditetapkan sebesar 0,43 dikarenakan tip speed rasio 7 penentuannya seperti terlihat pada gamb. 1. Untuk persamaan luas area sapuan turbin $\mathrm{S}$ :

$$
S=\frac{\pi D^{2}}{4}
$$

D adalah diameter sudu, sementara diameter sudu turbin dapat ditentukan dengan persamaan berikut

$$
D=\sqrt{\frac{8 P}{\rho C_{p} \pi V_{R}^{3}}}
$$

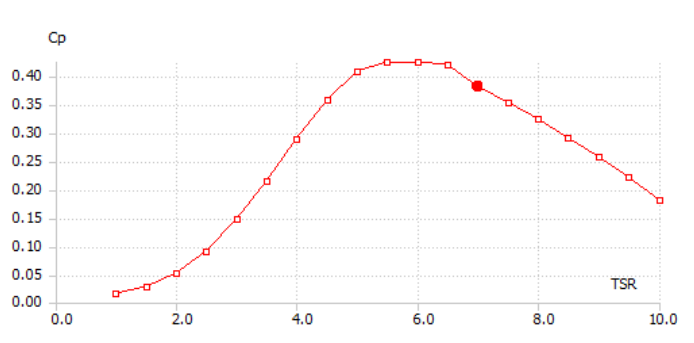

Gambar 1. Grafik hubungan koefisien daya dengan tip speed ratio (TSR)

Hasil disain Qblade NACA 4417

Untuk menentukan panjang chord sudu maka pendekatan persamaan Betz dapat diterapkan sebagai berikut :

$C=\frac{16 \pi r_{\max }\left(r_{\max } / r\right)}{9 \lambda^{2} B}$

[2]

$\mathrm{B}=$ banyaknya sudu turbin ( 3 sudu $)$

$\lambda=$ tip speed rasio

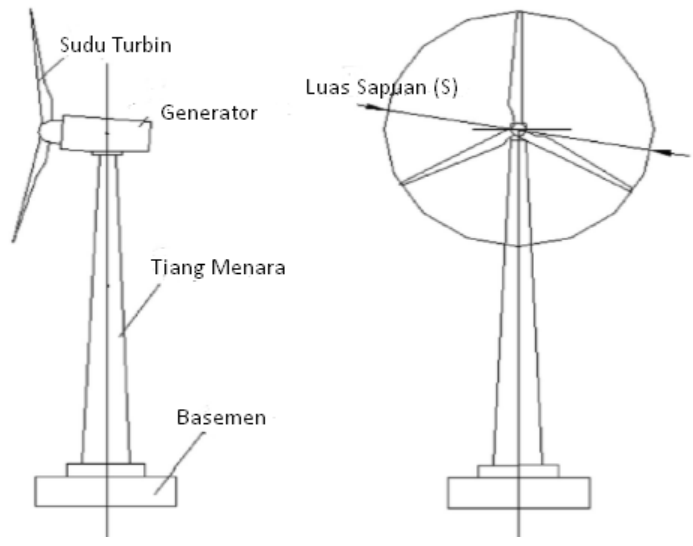

Gambar 2. Turbin Angin [1]

\subsection{Aerofoil sudu turbin angin}

Untuk mempermudah pembuatan sudu turbin perlu memahami dan merancang aerofoil beserta parameter - parameternya seperti panjang chord di root dan tip, tebal maksimum chord, mean chamber dan radius sudu turbin.

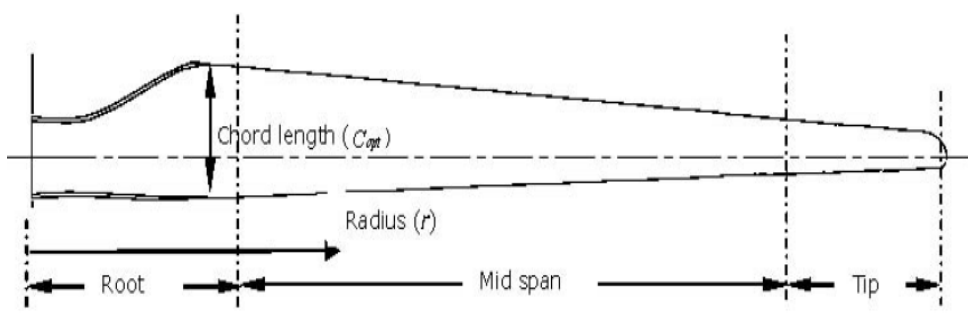

Gambar 3. Bentuk sudu turbin tampak atas [3]

Sudut hantaman angin ke sudu turbin dipilih $5^{0}$ berharap sudut tersebut dapat menghindari efek stall yang akan berpengaruh terhadap patahnya sudu.Pada penelitian ini bentuk sudu turbin menggunakan NACA 4417 yang artinya angka pertama menunjukkan prosentase chamber maksimum pada chord sebesar 4\%, angka kedua menerangkan letak chamber maksimum dari leading edge sebesar $40 \%$, sedangkan angka ketiga dan keempat yaitu 17 artinya ketebalan maksimum airofoil $17 \%$ dari chord.

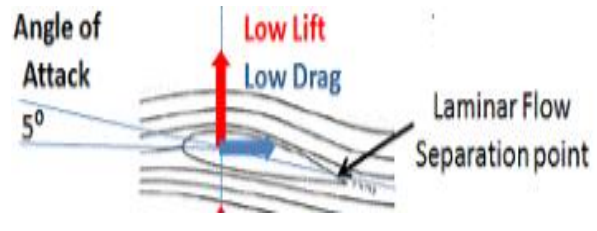

Gambar 4. Referensi angle attack ref. www.mpoweruk.com

Berikut adalah salah satu contoh tabel (tabel 1) untuk digunakan sebagai parameter merancang sudu turbin angin mengikuti kaidah profil NACA. 
Tabel 1.

Data sudu lengkap dengan profilnya [4]

\begin{tabular}{llrlll}
\hline $\begin{array}{l}\text { Station } \\
(\mathrm{m})\end{array}$ & $\begin{array}{l}\text { Chord } \\
(\mathrm{mm})\end{array}$ & $\begin{array}{l}\text { Thickness } \\
(\mathrm{mm})\end{array}$ & $\begin{array}{l}\text { Thickness } \\
(\%)\end{array}$ & $\begin{array}{l}\text { Twist } \\
(\text { degree })\end{array}$ & Profile NACA 63-621 = N21, FXS 66-196 = F196 \\
\hline 0.8 & 600 & 178 & 29.7 & 16.0 & $1.41(\mathrm{~N} 21)$ \\
1.2 & 562 & 163 & 29.0 & 12.8 & $1.38(\mathrm{~N} 21)$ \\
1.6 & 524 & 149 & 28.4 & 10.1 & $1.35(\mathrm{~N} 21)$ \\
2.0 & 486 & 134 & 27.6 & 7.8 & $1.31(\mathrm{~N} 21)$ \\
2.4 & 448 & 120 & 26.8 & 5.8 & $1.28(\mathrm{~N} 21)$ \\
2.8 & 410 & 105 & 25.6 & 4.2 & $1.22(\mathrm{~N} 21)$ \\
3.2 & 371 & 91 & 24.5 & 2.8 & $0.85(\mathrm{~N} 21)+0.34(\mathrm{~F} 196)$ \\
3.6 & 333 & 76 & 22.8 & 1.8 & $0.25(\mathrm{~N} 21)+0.90(\mathrm{~F} 196)$ \\
4.0 & 295 & 61 & 20.7 & 0.9 & $1.06(\mathrm{~F} 196)$ \\
4.4 & 257 & 47 & 18.3 & 0.4 & $0.93(\mathrm{~F} 196)$ \\
4.8 & 219 & 32 & 14.6 & 0.2 & $0.74(\mathrm{~F} 196)$ \\
5.0 & 200 & 25 & 12.5 & 0.0 & $0.64(\mathrm{~F} 196)$ \\
\hline
\end{tabular}

\section{Methodologi}

Metode yang digunakan adalah pendekatan persamaan teoritis dengan software Qblade NACA 4417, dimana untuk mendisain dengan software dibutuhkan juga perhitungan dari persamaan di literatur Alur penelitian disajikan pada gambar 5 .

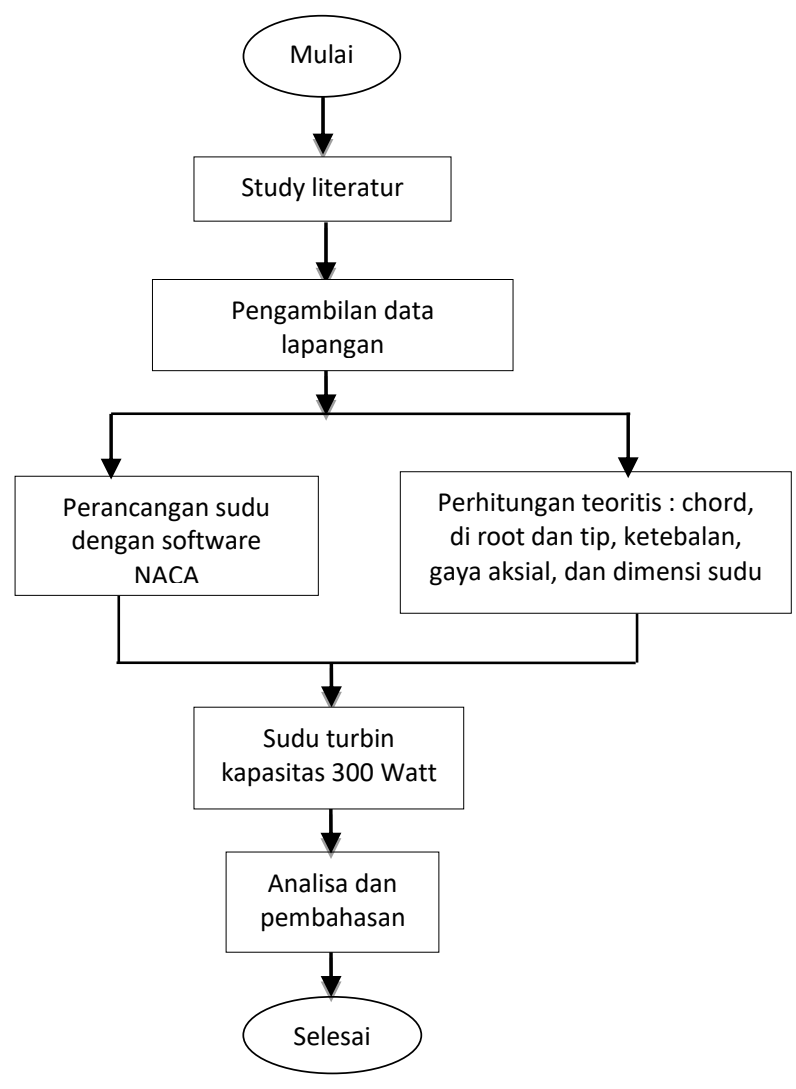

Gambar 5. Flow chart

\section{Hasil dan Pembahasan}

Berdasarkan hasil perhitungan yang telah dilakukan dengan menetapkan parameter awal yaitu kecepatan angin $4 \mathrm{~m} / \mathrm{s}$ berkapasitas 300 watt pada ketinggian 30 meter, dengan menganggap temperatur lingkungan $30^{\circ} \mathrm{C}$ maka didapat hasil perancangan sebagai berikut :

Tabel 2.

Parameter utama disain turbin

\begin{tabular}{|c|c|}
\hline Parameter & Nilai \\
\hline \begin{tabular}{llr} 
- & \multicolumn{2}{l}{ Daya yang diinginkan, $\mathrm{P}$} \\
- & Kecepatan angin, & $\mathrm{V}$ \\
- & Tip speed rasio, & $\mathrm{TSR}$ \\
- & Banyak sudu, & $\mathrm{B}$ \\
- & Profile aerofoil & \\
- & Sudut serang, & $\alpha$ \\
- & Diameter rotor, & $\mathrm{D}$ \\
- & Koefisien daya, & $\mathrm{Cp}$ \\
- & Massa jenis udara, $\quad \rho$ \\
- & Kecepatan putar rotor, $n$ \\
- & Luas sapuan, & $\mathrm{S}$ \\
- & Gaya dorong aksial, $\quad \mathrm{F}_{\mathrm{aksial}}$
\end{tabular} & $\begin{array}{l}: 300 \mathrm{~W} \\
: 4 \mathrm{~m} / \mathrm{s} \\
: 7 \\
: 3 \\
: \text { NACA } 4417 \\
: 5^{0} \\
: 4,76 \mathrm{~m} \\
: 0,43 \\
: 1,225 \mathrm{~kg} / \mathrm{m}^{3} \\
: 112 \mathrm{rpm} \\
: 5,7 \mathrm{~m}^{2} \\
: 119 \mathrm{~N}\end{array}$ \\
\hline
\end{tabular}

\subsection{Distribusi panjang chord.}

Dari gambar diatas root (pangkal) dan tip (ujung) mempunyai perbedaan dimana root merupakan area yang paling tebal dan berat sedangkan tip merupakan area berada di ujung sudu. Berdasarkan buku panduan elemen mesin terdapat tiga macam efisiensi $\eta$ yaitu bantalan 0,971 lengan adaptor 0,96 dan efisiensi transmisi roda gigi maka didapat total efisiensi $0,971 \mathrm{x}$ $0,96 \times 0,97=0,904$ Sehingga didapat daya input masuk $\mathrm{P}_{\text {input }}=300 / 0,904=332$ watt

\subsection{Analisa gaya turbin angin pada kondisi \\ kecepatan angin maksimal.}

Ketika turbin angin mengalami kondisi kecepatan angin maksimum maka keadaan tersebut adalah kondisi kritis sehingga diperlukan analisa gaya pada sistem komponen sudu, hub dan tiang penyangga. 
Untuk gaya maksimum arah sumbu z (posisi berhadapan sudu turbin) dengan asumsi kecepatan maksimum $7 \mathrm{~m} / \mathrm{s}$ adalah 119 Newton.

\subsection{Bentuk dan dimensi Sudu turbin}

Metode perancangan dimensi chord, ketebalan maksimum chord bentuk chord dilakukan pendekatan perancangan dengan menggunakan software Qblade untuk NACA tipe 4417. Disamping itu juga TSR $\leq 7$, sehingga memerlukan profil aerofoil dalam desain. Maka dipilih aerofoil NACA 4417 dengan karakteristik seperti pada gambar 6 .

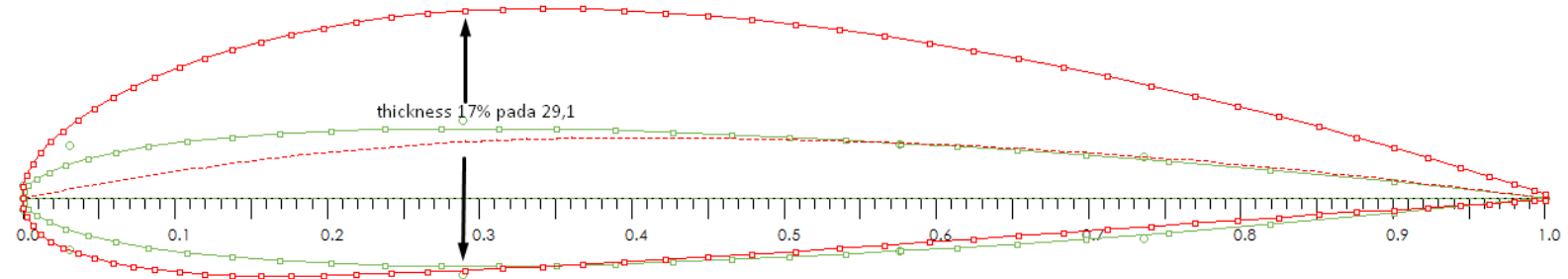

\begin{tabular}{|l|r|r|r|r|r|r|r|r|}
\hline \multicolumn{1}{|c|}{ Name } & Thickness (\%) & at (\%) & Camber (\%) & at (\%) & Points & TE Flap (deg) & TE XHinge & TE YHinge \\
\hline 1 Spline foil & 9.03 & 31.20 & 0.00 & 0.00 & 60 & 0.00 & 0.00 & 0.00 \\
\hline 2 & NACA 4417 & 17.00 & 29.10 & 4.00 & 39.50 & 99 & 0.00 & 0.00 \\
\hline
\end{tabular}

Gambar 6. Bentuk aerofoil NACA 4417

Gambar diatas adalah profil aerofoil yang ada di software Qblade untuk NACA 4417 dimana garis berwarna merah adalah garis NACA sedangkan yang warna hijau adalah garis Spline foil. Arti 17\% adalah ketebalan maksimum dari chord yang telah dihitung dari persamaan (4) pada posisi $d r$ yang diberikan di tabel 3. Dengan demikian panjang dan tebal chord akan berkurang sampai di radius ujung (tip) sudu turbin. Dalam pembuatan sudu turbin dilakukan perhitungan panjang chord dan ketebalan maksimum chord disetiap penampang (12 penampang) seperti tampak pada tabel sehingga akan muncul bentuk sudu seperti gambar 8 . Penetapan sudut serang $5^{0}$ untuk menghindari dari stall/ kehilangan dari gaya angkat pada airfoil.

Tabel. 3

Stasion, panjang dan ketebalan chord

\begin{tabular}{|c|c|c|c|c|c|c|}
\hline Penampang & $\mathrm{dr}(\mathrm{m})$ & $\mathrm{R}(\mathrm{m})$ & Lambda & $\mathrm{B}$ & $\mathrm{C}(\mathrm{m})$ & $\begin{array}{c}\text { Maks_thickness } \\
(\mathbf{m}) \text { atau } \mathbf{0 , 1} 7^{*} \mathrm{C}\end{array}$ \\
\hline 1 & 0,3 & 2,4 & 7 & 3 & 0,73 & 0,124 \\
\hline 2 & 0,4 & 2,4 & 7 & 3 & 0,55 & 0,093 \\
\hline 3 & 0,6 & 2,4 & 7 & 3 & 0,36 & 0,062 \\
\hline 4 & 0,8 & 2,4 & 7 & 3 & 0,27 & 0,046 \\
\hline 5 & 1 & 2,4 & 7 & 3 & 0,22 & 0,037 \\
\hline 6 & 1,2 & 2,4 & 7 & 3 & 0,18 & 0,031 \\
\hline 7 & 1,4 & 2,4 & 7 & 3 & 0,16 & 0,027 \\
\hline 8 & 1,6 & 2,4 & 7 & 3 & 0,14 & 0,023 \\
\hline 9 & 1,8 & 2,4 & 7 & 3 & 0,12 & 0,021 \\
\hline 10 & 2 & 2,4 & 7 & 3 & 0,11 & 0,019 \\
\hline 11 & 2,2 & 2,4 & 7 & 3 & 0,10 & 0,017 \\
\hline 12 & 2,4 & 2,4 & 7 & 3 & 0,09 & 0,015 \\
\hline
\end{tabular}

Tampak dari tabel 3 jari-jari $0-0,29 \mathrm{~m}$ adalah bentuk circular point yang nantinya akan dikopel dengan hub sedangkan di jari-jari 0,3 m sudah dibentuk sudu NACA.

Dari gambar 7 tampak bentuk aerofoil yang diharapkan dengan panjang dari hub ke pangkal sudu sebesar 2,4 m sedangkan ketebalan maksimum di root $0,124 \mathrm{~m}$ dan di tip $0,015 \mathrm{~m}$. Untuk membuat bentuk chord di software Qblade panjang chord ditentukan dari perhitungan teoritis yaitu pada $\mathrm{r}(0,3 \mathrm{~m})=0,730 \mathrm{~m}$.

\section{Simpulan}

Berdasarkan sumber data kecepatan angin di Gedung rektorat Universitas Muhammadiyah Riau, telah dilakukan disain turbin angin dengan kapasitas daya 300 Watt. Bentuk dan dimensi sudu turbin yang direncanakan mengikuti profil NACA 4417 dengan radius $2,4 \mathrm{~m}$. Gambar rancangan dari hasil penelitian ini akan menjadi acuan dalam pembuatan sudu turbin angin berbahan baku lokal limbah pelepah sawit 


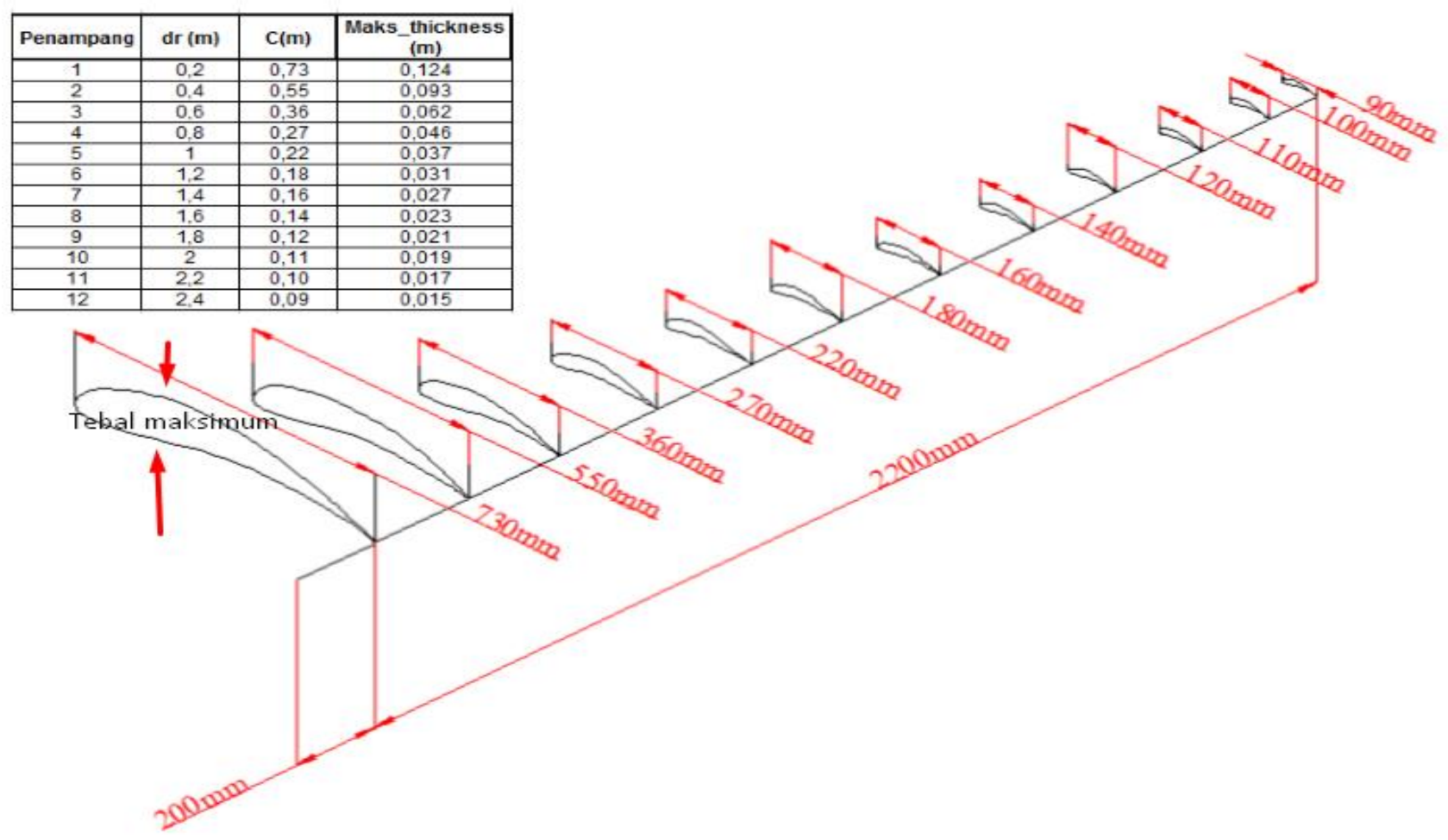

Gambar 7. Bentuk dan dimensi aerofoil sudu turbin

\section{Daftar Pustaka}

[1] Wenyi Liu, 2016 "Design and kinetic analysisi of wind turbine blade-hub-tower coupled system" Journal Renewable energy, School Mechanical and electrical engineering Jiansu Normal University Xuzhou China. www.sciencedirect.com

[2] Amano et all 2009 "Design and Testing of Low Speed Wind Turbine Blade" Proceeding of the ASME 2009 International Mechanical Engineering Congress \& Exposition IMECE 2009. www.sciencedirect.com

[3] Peter J Schubel et all, 2012 "Wind Turbine Blade Design" mdpi journal energi ISSN 1996-1073 faculty engineering Division of Material and Structure, Nottingham UniversityNG7 2RD, UK www.sciencedirect.com

[4] S.M. Habali, I.A. Saleh, 2000 "Local design, testing and manufacturing of small mixed airfoil wind turbine blades of glass ®ber reinforced plastics Part I: Design of the blade and root" Energy Conversion \& Management. www.sciencedirect.com 